\title{
BMJ Open Prospective, single-centre, randomised controlled trial to evaluate the efficacy and safety of ischaemia-free liver transplantation (IFLT) in the treatment of end-stage liver disease
}

Changjun Huang (D) , ,2,3 Shanzhou Huang, ${ }^{1,2,3}$ Yunhua Tang, ${ }^{1,2,3}$ Qiang Zhao, ${ }^{1,2,3}$ Dongping Wang, ${ }^{1,2,3}$ Weiqiang Ju, ${ }^{1,2,3}$ Lu Yang, ${ }^{4}$ Jian Zhang, ${ }^{5}$ Linwei Wu, ${ }^{1,2,3}$ Maogen Chen, ${ }^{1,2,3}$ Zhiheng Zhang, ${ }^{1,2,3}$ Zebin Zhu, ${ }^{1,2,3}$ Linhe Wang, ${ }^{1,2,3}$ Caihui Zhu, ${ }^{1,2,3}$ Yixi Zhang, ${ }^{1,2,3}$ Chengjun Sun, ${ }^{1,2,3}$ Wei Xiong, ${ }^{4}$ Yuekun Shen, ${ }^{4}$ Xiaoxiang Chen, ${ }^{4}$ Yi Ma, ${ }^{1,2,3}$ Anbin Hu, ${ }^{1,2,3}$ Xiaofeng Zhu, ${ }^{1,2,3}$ Jian Rong, ${ }^{6}$ Changjie Cai, ${ }^{7}$ Zhiyong Guo, ${ }^{1,2,3}$ Xiaoshun $\mathrm{He}^{1,2,3}$

To cite: Huang C, Huang S, Tang Y, et al. Prospective, single-centre, randomised controlled trial to evaluate the efficacy and safety of ischaemia-free liver transplantation (IFLT) in the treatment of end-stage liver disease. BMJ Open 2020;10:e035374. doi:10.1136/ bmjopen-2019-035374

- Prepublication history for this paper is available online To view these files, please visit the journal online (http://dx.doi. org/10.1136/bmjopen-2019035374).

\section{$\mathrm{CH}, \mathrm{SH}$ and $\mathrm{YT}$ contributed} equally.

$\mathrm{CH}, \mathrm{SH}$ and $\mathrm{YT}$ are joint first authors.

Received 29 0ctober 2019 Revised 17 February 2020 Accepted 19 February 2020

Check for updates

(C) Author(s) (or their employer(s)) 2020. Re-use permitted under CC BY-NC. No commercial re-use. See rights and permissions. Published by BMJ.

For numbered affiliations see end of article.

Correspondence to Professor Xiaoshun He; gdtrc@163.com and Professor Zhiyong Guo; rockyucsf1981@126.com

\section{ABSTRACT}

Introduction During conventional liver transplantation (CLT), ischaemia-reperfusion injury (IRI) is inevitable and is associated with complications such as early allograft dysfunction (EAD), primary non-function and ischaemictype biliary lesions. We have established a novel procedure called ischaemia-free liver transplantation (IFLT). The results from a pilot study suggest that IFLT might prevent IRI and yield better transplant outcomes than CLT. The purpose of this study was to further assess the efficacy and safety of IFLT versus CLT in patients with end-stage liver disease.

Methods and analysis This is an investigator-initiated, open-label, phase III, prospective, single-centre randomised controlled trial on the effects of IFLT in patients with endstage liver disease. Adult patients (aged 18-75 years) eligible for liver transplantation will be screened for participation in this trial and will be randomised between the IFLT group ( $n=34)$ and the CLT group $(n=34)$. In the IFLT group, the donor liver will be procured, preserved and implanted with continuous normothermic machine perfusion (NMP). In the CLT group, the donor liver will be procured after a fast cold flush, preserved in $0^{\circ} \mathrm{C}-4^{\circ} \mathrm{C}$ solution and implanted under hypothermic and hypoxic conditions. Patients in both groups will be managed according to the standard protocol of our centre. The primary end point is the incidence of EAD after liver transplantation. Intraoperative and postoperative parameters of donor livers and recipients will be observed and recorded, and postoperative liver graft function, complications and recipient and graft survival will be evaluated. After a 12-month follow-up of the last enrolled recipient, the outcomes will be analysed to evaluate the safety and efficacy of IFLT versus CLT in patients with endstage liver disease.

Ethics and dissemination The protocol was reviewed and approved by the Ethics Committee of The First Affiliated Hospital of Sun Yat-sen University. The findings will be disseminated to the public through conference presentations and peer-reviewed scientific journals.

\section{Strengths and limitations of this study}

This study is the first to compare the efficacy and safety of ischaemia-free liver transplantation (IFLT) and conventional liver transplantation (CLT) in the treatment of end-stage liver disease in a randomised controlled clinical trial.

- The inclusion of a series of well-designed end points and multiple research parameters will enable an indepth analysis of the effects of IFLT on human liver transplantation.

- The randomisation design will allow us to achieve a homogeneous distribution of patients between IFLT and CLT.

- The open-label design is considered a limitation of this trial, and due to the nature of the surgical procedure, it is not possible to blind the surgical team to the group allocation.

Trial registration number ChiCTR1900021158.

\section{INTRODUCTION}

\section{Background and rationale}

Over the past several decades, liver disease has become one of the leading causes of death and illness worldwide. ${ }^{1}$ One-fifth of the population in China suffers from some kind of liver disease, and the number of patients with end-stage liver disease remains high. ${ }^{2}$ Liver transplantation has been acknowledged as the only effective treatment for end-stage liver diseases. ${ }^{3}$ Although the shortterm outcome of organ transplantation has made certain progress in recent years, the long-term outcome has not been significantly improved. ${ }^{4}$ Meanwhile, organ shortage 
has become a worldwide issue, with a large number of patients dying on the waiting list for liver transplantation. ${ }^{56}$ Hence, further improvement of transplant efficacy and expansion of the donor organ pool have attracted great attention in the field of organ transplantation.

During the process of conventional organ transplantation, organs are procured after a fast cold flush, preserved in $0^{\circ} \mathrm{C}-4^{\circ} \mathrm{C}$ solution and implanted under hypothermic and hypoxic conditions. ${ }^{7-9}$ The organs can suffer ischaemic injuries during the whole transplant procedure, so ischaemia-reperfusion injury (IRI) is an inevitable event in all types of organ transplantation. ${ }^{10}{ }^{11}$ IRI brings about allograft dysfunction and undermines the function of other organs, giving rise to a series of complications and even patient death. ${ }^{13}$ The incidences of early graft dysfunction (EAD), primary non-function (PNF) and ischaemic-type biliary lesions (ITBL) after liver transplantation are around $10 \%-50 \%, 3 \%-7 \%$ and $5 \%-10 \%$, respectively. ${ }^{14-17}$ For decades, researchers have been making efforts to reduce the morbidity and mortality related to IRI. However, owing to the complex molecular mechanisms of IRI, interventions such as drugs, stem cells and protective gases exert little effect. ${ }^{18} 19$

In the past decade, there have been tremendous achievements in the field of machine perfusion technology. It has been demonstrated that both normothermic machine perfusion (NMP) and hypothermic oxygenated machine perfusion (HOPE) can alleviate allograft IRI and improve transplant outcomes in animal experiments and clinical trials. ${ }^{20-23}$ Particularly, conditions close to physiological status are provided to the grafts during ex vivo NMP. Therefore, organ repair and graft viability assessment can be achieved during NMP. The technique has been successfully applied in lung, liver, kidney and heart transplantation. ${ }^{20-26}$ However, under the current practice, ischaemic injuries of organs first occur during procurement and preparation, before the initiation of NMP and then once again during implantation after NMP. Therefore, the organs might suffer a 'double hit' of IRI.

We therefore hypothesise that continuous oxygenated blood supply to the donor liver during the entire period of donor liver procurement, preservation and implantation could prevent IRI and significantly reduce the incidence of complications induced by IRI. We established a reliable ischaemia-free liver transplantation (IFLT) technique in pigs and reported the first case of IFLT in humans. ${ }^{27}{ }^{28}$ During IFLT, the blood supply to the donor livers is continuously maintained throughout the whole process of procurement, preservation and implantation. The results of the first 14 cases of IFLT showed that EAD occurred in 1 case $(7.1 \%)$, compared with in $25(53.2 \%)$ out of 47 cases of conventional liver transplantation (CLT) with standard static cold storage (SCS) in the same period. The peak alanine aminotransferase (AST) (369 U/L vs $1502 \mathrm{U} / \mathrm{L}, \mathrm{p}<0.001)$ and peak aspartate aminotransferase (ALT) $(201 \mathrm{U} / \mathrm{L}$ vs $689 \mathrm{U} / \mathrm{L}, \mathrm{p}<0.001)$ within 7 days posttransplantation were significantly decreased in the IFLT versus the CLT group. Histological studies showed that in sharp contrast to CLT, there was no augmentation in the Suzuki score, hepatocyte apoptosis, inflammatory cytokines, chemokines or activation of inflammatory pathways after reperfusion in the IFLT group.

Although the pilot study suggested promising transplant outcomes of IFLT, the design of the study was nonrandomised, and patient selection bias could not be ruled out. The purpose of this study was to further explore the efficacy and safety of IFLT in a prospective, randomised controlled trial.

\section{Objectives}

Primary objective

To compare the incidence of IRI-related complications between IFLT and CLT recipients, as well as the allograft/ recipient survival rate, to further validate the clinical efficacy and safety of IFLT.

\section{Secondary objective}

To compare the severity of allograft IRI between IFLT and CLT by laboratory analysis of peripheral blood and liver biopsy specimens.

\section{METHODS}

This protocol was designed to conform with the Standard Protocol Items: Recommendations for Interventional Trials 2013 statement. $^{29}$

\section{Study setting}

The study will be conducted at The First Affiliated Hospital, Sun Yat-sen University.

\section{Eligibility criteria}

The following inclusion and exclusion criteria will be applied when recruiting donors and recipients. Only donors and recipients meeting these criteria will be recruited into the study.

\section{Donor inclusion criteria}

1. Donation after brain death (DBD).

2. Over the age of 18 years, or over the age of 14 years with body weight $>50 \mathrm{~kg}$.

3. The donor liver is allocated to a recipient at our own hospital.

\section{Recipient inclusion criteria}

1. Age $18-75$ years.

2. End-stage liver disease and active on the waiting list for liver transplantation.

3. Agreed to receive liver grafts from deceased donors.

4. Able to give informed consent.

5. Able to comply with the study protocol.

\section{Donor exclusion criteria}

1. Liversintended for split or reduced-size transplantation.

2. High risk of transmitted infections (HIV infection and active tuberculosis). 
3. Risk of donor malignancy transmission over $10 \%$ according to the Disease Transmission Advisory Committee categorisations. ${ }^{30}$

Recipient exclusion criteria

1. Waiting for multivisceral or combined organ transplantation.

2. ABO-incompatible liver transplantation.

3. Primary liver cancer beyond the University of California at San Francisco (UCSF) criteria. ${ }^{31}$

4. Fulminant liver failure.

5. Current pregnancy.

6. A history of organ transplantation.

7. Contraindications defined by the American Association for the Study of Liver Diseases liver transplant practice guidelines ${ }^{32}$ except model for end-stage liver disease score $<15$.

\section{Interventions}

\section{Screening}

All preoperative evaluation and eligibility scrutiny must be accomplished before randomisation to ensure that the donor and recipient match all inclusion criteria. The investigator will create a screening log to record the details of all selected donors and recipients to confirm their eligibility or ineligibility.

1. Donors: when a potential donor comes into sight, brain death should be confirmed by two doctors. Medical history-taking and preoperative evaluation should be conducted following the study protocol. Eligibility will be determined according to inclusion and exclusion criteria. The schedule for donor screening is summarised in table 1 .

2. Recipients: when an end-stage liver disease patient is enrolled on the waiting list, medical history-taking and

\begin{tabular}{lll}
\hline Table 1 & The schedule for donor screening & \\
\hline Contents & $\begin{array}{l}\text { Screening } \\
\text { stage }\end{array}$ & $\begin{array}{l}\text { Retrieval } \\
\text { day }\end{array}$ \\
\hline Time & -7 Days-Day 0 & Day 0 \\
Written informed consent & $\times$ & \\
Eligibility assessment & $\times$ & \\
Patient history & $\times$ & \\
\hline Demographic data & $\times$ & $\times$ \\
Vital signs & $\times$ & \\
\hline Physical examination & $\times$ & \\
Standard routine blood tests & $\times$ & $\times$ \\
\hline Standard routine examinations & $\times$ & \\
\hline Collection of blood specimens & & \\
\hline Liver biopsy & \\
\hline
\end{tabular}

Standard routine blood tests: blood type, blood/urine/stool routine test, coagulation function, communicable and infectious diseases, blood gas analysis, electrolytes, liver/renal/heart/function tests. Standard routine examinations: ECG, chest X-ray, cardiac and abdominal colour ultrasound and head/chest/abdomen CT scan.

\begin{tabular}{lll} 
Table 2 & The schedule for recipient screening \\
\hline Contents & Screening stage & Transplant day \\
\hline Time & -30 Days-Day 0 & Day 0 \\
Written informed & $\times$ & \\
consent & & \\
Eligibility assessment & $\times$ & \\
Patient history & $\times$ & \\
Demographic data & $\times$ & $\times$ \\
Vital signs & $\times$ & $\times$ \\
Physical examination & $\times$ & \\
$\begin{array}{l}\text { Performance status } \\
\text { (ECOG) }\end{array}$ & & $\times$ \\
Quality of life (EQ-5D) & & \\
$\begin{array}{l}\text { Standard routine } \\
\text { blood tests }\end{array}$ & $\times$ & \\
$\begin{array}{l}\text { Standard routine } \\
\text { examinations }\end{array}$ & $\times$ & $\times$ \\
$\begin{array}{l}\text { Collection of blood } \\
\text { specimens }\end{array}$ & & \\
Liver biopsy & & \\
Others & & \\
\hline
\end{tabular}

Standard routine blood tests: blood type, blood/urine/stool routine test, coagulation function, communicable and infectious diseases, electrolytes, liver/renal/heart/function tests.

Standard routine examinations: ECG, chest X-ray, lung function, cardiac and abdominal colour ultrasound and abdomen CT scan. Other parameters, such as magnetic resonance, blood gases, tumour markers and hepatitis B virus DNA, are measured according to clinical conditions.

ECOG, Eastern Cooperative Oncology Group; EQ-5D, EuroQol-5 Dimension.

preoperative evaluation should be conducted following the study protocol. Eligibility will be determined according to inclusion and exclusion criteria. The schedule for recipient screening is summarised in table 2.

\section{Donor and recipient matching}

1. Donor livers are allocated to recipients by the China Organ Transplant Response System (COTRS) according to blood type, patient condition, waiting time and other routine allocation principles.

2. After an eligible donor liver is allocated to an eligible recipient in our centre, the donor and recipient are assigned to the experimental group (IFLT group) or control group (CLT group) based on randomisation.

Surgical procedures (IFLT versus CLT) Ischaemia-free liver transplantation

Donor livers from the IFLT group will undergo continuous NMP during procurement, preservation and implantation. ${ }^{27}$

\section{Ischaemia-free procurement of donor liver}

Mobilisation of the liver is conducted with a precise technique. A tube is placed in the common bile duct for bile 
drainage, and the cystic duct is ligated. The coeliac artery (CA), gastroduodenal artery (GDA), splenic artery (SA), inferior vena cava (IVC) and portal vein (PV) are well dissected. An 8-Fr/12-Fr arterial cannula is inserted into the GDA or SA without interruption of arterial supply for the liver from the CA. The arterial cannula is connected to the hepatic artery (HA) perfusion line of the Liver Assist (Organ Assist, Groningen, The Netherlands). A 3 $\mathrm{cm}$ long right external iliac vein is harvested and end-toside anastomosed to the portal vein with partial blockage of the $\mathrm{PV}$ for constructing an interposition vein. A straight 24-Fr cannula is connected to the PV perfusion line of the Liver Assist and then inserted into the PV via the interposition vein. A 32-Fr to 34-Fr caval cannula is placed in the infrahepatic inferior vena cava (IHIVC) for outflow to the organ reservoir of the Liver Assist. The venous drainage of the suprahepatic inferior vena cava (SHIVC) to the right atrium is blocked. Then the in situ circuit is established, and NMP is started. The liver is harvested and transferred to the organ reservoir under continuous NMP. Immediately after the liver is removed from the abdominal cavity, the kidneys are cold-flushed via the cannula within the abdominal aorta and procured.

\section{Ischaemia-free preservation of donor liver}

The liver is transferred to the perfusion device. The caval cannula is removed immediately when the liver is moved to the organ reservoir. The liver graft is subjected to continuous ex situ NMP until allograft re-vascularisation. The $\mathrm{PV}$ perfusion pressure is set at $6-10 \mathrm{~mm} \mathrm{Hg}$ with a targeted flow rate $>500 \mathrm{~mL} / \mathrm{min}$. The hepatic artery pressure is set at $50-60 \mathrm{~mm} \mathrm{Hg}$ with a targeted flow rate $>150 \mathrm{~mL} / \mathrm{min}$. During the NMP, the pressure and flow rate are monitored and adjusted to within an appropriate range. Redundant tissues are removed from the liver and blood vessels. The SHIVC and IHIVC are examined for leaks by transient blockage of the IVC. The bile tube is connected to a collection container. The amount of bile production is recorded, and the biochemical parameters is monitored every $60 \mathrm{~min}$. Perfusate samples are taken for blood gas analysis every 10-20 min and liver function tests every $30 \mathrm{~min}$ to monitor the biochemical parameters. The viability of the liver is assessed by blood gas analysis and liver function tests of the perfusate, as well as bile biochemical parameters, as previously reported. ${ }^{33}$ For the safety of patients, the viability of grafts during NMP is confirmed before we start the recipient surgical procedures.

\section{Ischaemia-free implantation of donor liver}

The diseased liver is resected using a routine procedure. The donor IHIVC is re-cannulated, and the SHIVC is blocked by a clamp. Then the donor liver is moved from the reservoir and placed in the recipient's abdominal cavity so that an in situ NMP circuit is re-established. The donor SHIVC is anastomosed to the recipient counterparts in a corresponding fashion using 3-0 Prolene based on the bicaval or piggy-back technique. The donor PV and $\mathrm{HA}$ are anastomosed to the recipient counterparts in an end-to-end fashion using 5-0 and 7-0 Prolene, respectively. Because of the native and artificial branches on the HA and PV, all these anastomoses are accomplished under continuous NMP of the allograft. After that, the clamps on the PV and HA are released so that the native dual blood supply for the liver is re-established. At the same time, NMP ceases after removal of the HA and PV cannula. Then the cannula within IHIVC is removed, and around $200 \mathrm{~mL}$ perfusate within the liver is flushed out, followed by release of the clamp on the SHIVC. The anhepatic phase is over. The donor SA or GDA is ligated closed, and the interposition vein is sutured closed. The donor IHIVC is then anastomosed to the recipient IHIVC or ligated according to the bicaval or piggy-back technique used. The donor common bile duct is end-to-end anastomosed to the recipient common bile duct after withdrawal of the draining tube. After meticulous haemostasis and abdominal closure, the patient is sent to the post-transplant intensive care unit (ICU).

\section{Recording and assessment of NMP parameters}

In the process of NMP, the stability and efficacy of perfusion are monitored, and liver graft function is monitored by perfusate biochemical tests and blood gas analysis. The perfusion parameters, regulatory measures, bile production and blood gas analysis results are recorded. NMP parameters are summarised in tables 3-7.

\section{Conventional liver transplantation}

Following the standard in situ cold flushing procedure, the liver will be retrieved and placed in ice-cold University of Wisconsin solution. Back-table preparation will be performed under standard procedures prior to implantation. After removal of the diseased liver, the donor liver is transferred to the abdominal cavity. Following anastomosis of the IVC and PV, the vessels are re-opened to restore the blood supply of the allograft. Then the donor artery and bile duct are anastomosed successively. After meticulous haemostasis and abdominal closure, the patient is sent to the ICU.

\section{Intraoperative monitoring}

The recipient's condition during operation and anaesthesia will be recorded according to the standards and norms of our centre. Intraoperative monitoring will be conducted to compare the impacts of IFLT or CLT on the functions of the donor liver and other organs, such as the heart, lung, kidney, intestine and brain.

\section{Postoperative management}

Both groups are managed according to the patients' conditions and standard protocols of our centre.

\section{Follow-up}

The patients will be followed up for 1 year. Postoperative visits will be performed on postoperative day (POD) $1-7$, POD 14 and each month post-transplantation. Biomedical 
Table 3 Blood gas analysis during perfusion

\begin{tabular}{|c|c|c|c|c|c|c|c|c|c|c|c|c|c|c|}
\hline Time (min) & 10 & 20 & 30 & 40 & 60 & 80 & 100 & 120 & 140 & 160 & 180 & 200 & $\ldots$ & 420 \\
\hline \multicolumn{15}{|l|}{$\mathrm{pH}$} \\
\hline \multicolumn{15}{|l|}{$\mathrm{PCO}_{2}(\mathrm{~mm} \mathrm{Hg})$} \\
\hline \multicolumn{15}{|l|}{$\mathrm{PO}_{2}(\mathrm{~mm} \mathrm{Hg})$} \\
\hline \multicolumn{15}{|l|}{$\mathrm{BE}(\mathrm{mmol} / \mathrm{L})$} \\
\hline \multicolumn{15}{|l|}{$\mathrm{HCO}_{3}^{-}(\mathrm{mmol} / \mathrm{L})$} \\
\hline \multicolumn{15}{|l|}{$\mathrm{sO}_{2}(\%)$} \\
\hline \multicolumn{15}{|l|}{ Lac (mmol/L) } \\
\hline \multicolumn{15}{|l|}{$\mathrm{Na}^{+}(\mathrm{mmol} / \mathrm{L})$} \\
\hline \multicolumn{15}{|l|}{$\mathrm{K}^{+}(\mathrm{mmol} / \mathrm{L})$} \\
\hline \multicolumn{15}{|l|}{$\mathrm{Cl}^{-}(\mathrm{mmol} / \mathrm{L})$} \\
\hline \multicolumn{15}{|l|}{ iCa (mmol/L) } \\
\hline \multicolumn{15}{|l|}{ GLU (mmol/L) } \\
\hline \multicolumn{15}{|l|}{ Hct } \\
\hline $\mathrm{Hb}(\mathrm{g} / \mathrm{L})$ & & & & & & & & & & & & & & \\
\hline
\end{tabular}

$\mathrm{BE}$, base excess; $\mathrm{Cl}^{-}$, chloride ion; $\mathrm{GLU}$, glucose; $\mathrm{Hb}$, haemoglobin; $\mathrm{HCO}_{3}^{-}$, bicarbonate ion; Hct, haematocrit; iCa, ionised calcium; $\mathrm{K}^{+}$, potassium ion; Lac, lactate; $\mathrm{Na}^{+}$, sodium ion; $\mathrm{PCO}_{2}$, partial pressure of carbon dioxide; $\mathrm{pH}$, pondus hydrogenii; $\mathrm{PO}_{2}$, partial pressure of oxygen; $\mathrm{sO}_{2}$, oxygen saturation.

values, complications, adverse events and medication administration records will be documented. Follow-up information is shown in tables 8-10.

\section{Outcomes}

Primary end point

The primary end point is the incidence of EAD within 7 days post-transplantation. The diagnosis of EAD is defined according to the presence of one or more of the following criteria ${ }^{34}$ :

1. Peak AST $>2000 \mathrm{IU} / \mathrm{L}$ within the first seven postoperative days.

2. Peak ALT $>2000 \mathrm{IU} / \mathrm{L}$ within the first seven postoperative days.

3. Total bilirubin (Tbil) $\geq 10 \mathrm{mg} / \mathrm{dL}$ on POD 7 (exclusion of biliary stricture).

4. International normalised ratio (INR) $\geq 1.6$ on POD 7 .
Secondary end points

1. Post-transplant peak AST: to ensure consistency, serum AST will be measured 5-11 hours postreperfusion on POD 1 and at $6-8$ am on POD 2-7, and the peak level will be defined as the highest of these values (in IU/L)..$^{35}$

2. Post-transplant peak ALT: serum ALT will be measured, and the peak level will be defined as AST.

3. Tbil on POD 7.

4. INR on POD 7.

5. AST, ALT, Tbil, INR, gamma-glutamyl transpeptidase, alkaline phosphatase and lactate dehydrogenase at POD 1-7, POD 14, postoperative month (POM) 1, POM 6 and POM 12.

6. Lactate level at 1 hour postreperfusion by arterial blood gas analysis.

\begin{tabular}{|c|c|c|c|c|c|c|c|c|c|c|}
\hline \multicolumn{2}{|l|}{ Time (min) } & $0-20$ & 20 & $20-40$ & 40 & $40-60$ & 60 & $60-80$ & $80-100$ & $\ldots \quad 420$ \\
\hline Additive & Sterile water $(\mathrm{mL})$ & & & & & & & & & \\
\hline & Gelofusine (mL) & & & & & & & & & \\
\hline & Alkaline solution $(\mathrm{mL})$ & & & & & & & & & \\
\hline & $10 \%$ Calcium chloride $(\mathrm{mL})$ & & & & & & & & & \\
\hline & Heparin $(U)$ & & & & & & & & & \\
\hline & Vasoactive drugs & & & & & & & & & \\
\hline & Gas & & & & & & & & & \\
\hline & Others & & & & & & & & & \\
\hline
\end{tabular}




\begin{tabular}{|c|c|c|c|c|c|c|c|c|c|c|c|c|c|c|c|c|c|c|c|}
\hline \multirow{2}{*}{$\begin{array}{l}\text { Hour } \\
\text { Min }\end{array}$} & \multicolumn{6}{|l|}{1} & \multicolumn{6}{|l|}{2} & \multirow[t]{2}{*}{$\ldots$} & \multicolumn{6}{|l|}{8} \\
\hline & 0 & 10 & 20 & 30 & 40 & 50 & 0 & 10 & 20 & 30 & 40 & 50 & & 0 & 10 & 20 & 30 & 40 & 50 \\
\hline $\begin{array}{l}\text { Flow rate }(\mathrm{mL} / \\
\text { min) }\end{array}$ & & & & & & & & & & & & & & & & & & & \\
\hline $\mathrm{T}\left({ }^{\circ} \mathrm{C}\right)$ & & & & & & & & & & & & & & & & & & & \\
\hline $\begin{array}{l}\text { Pressure }(\mathrm{mm} \\
\mathrm{Hg})\end{array}$ & & & & & & & & & & & & & & & & & & & \\
\hline $\begin{array}{l}\text { Flow rate }(\mathrm{mL} / \\
\text { min) }\end{array}$ & & & & & & & & & & & & & & & & & & & \\
\hline
\end{tabular}

$H A$, hepatic artery; PV, portal vein; R, resistance index; T, temperature.

7. Incidence of PNF: PNF is defined as unavoidable graft dysfunction requiring emergency re-transplantation or leading to death within the first 10 days posttransplantation, in the absence of surgical or immunological factors. 1936

8. Postreperfusion syndrome (PRS): PRS is defined as a decrease in mean arterial pressure $\geq 30 \%$ in comparison with the baseline value, for at least $1 \mathrm{~min}$, occurring during the first 5 min after reperfusion of the donor liver (without clamping of hepatic hilum). ${ }^{37}$

9. Biliary complications include but are not limited to bile leakage, anastomotic stenosis and ITBL. IBTLs are non-anastomotic strictures and dilations involving only the biliary tree of the graft in the absence of hepatic artery thrombosis. ${ }^{38} 39$

10. Patient survival status at POM 1, POM 6 and POM 12. 11. Graft survival status at POM 1, POM 6 and POM 12.

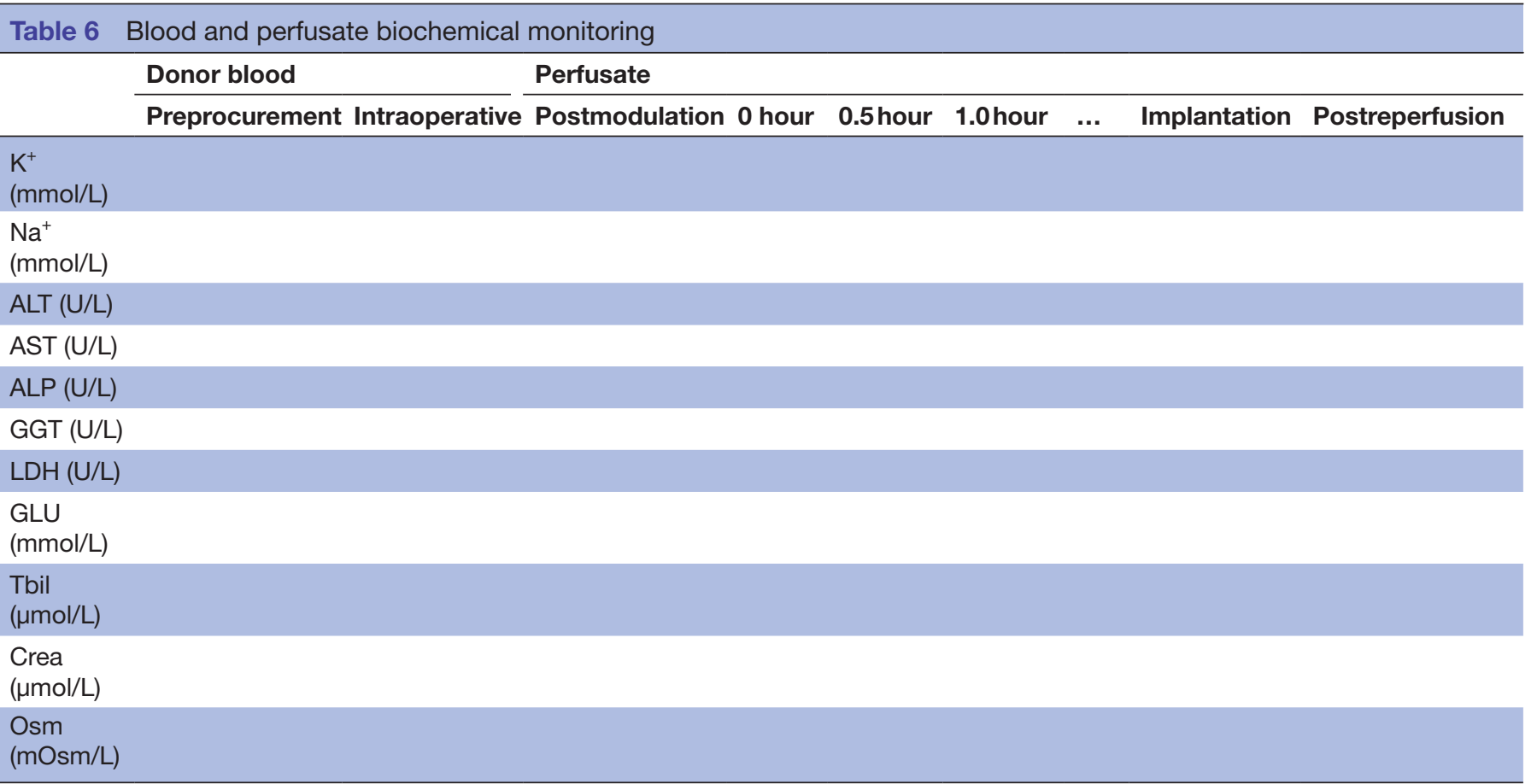

ALP, alkaline phosphatase; ALT, alanine aminotransferase; AST, aspartate transaminase; Crea, creatinine; GGT, glutamyl transpeptidase; GLU, glucose; $\mathrm{K}^{+}$, potassium ion; $\mathrm{LDH}$, lactate dehydrogenase; $\mathrm{Na}^{+}$, sodium ion; Osm, osmotic pressure; Tbil, total bilirubin. 
Table 7 Bile composition monitoring

Procurement 1 hour 2 hours 3 hours 4 hours 5 hours 6 hours 7 hours 8 hours Implantation Reperfusion

Bile produce

(mL/hour)

$\mathrm{pH}$

$\mathrm{PCO}_{2}{ }^{(\mathrm{mm} \mathrm{Hg})}$

$\mathrm{PO}_{2}{ }^{(\mathrm{mm} \mathrm{Hg})}$

$\mathrm{BE}(\mathrm{mmol} / \mathrm{L})$

$\mathrm{HCO}_{3}^{-}$

$(\mathrm{mmol} / \mathrm{L})$

$\mathrm{sO}_{2}(\%)$

$\mathrm{Lac}(\mathrm{mmol} / \mathrm{L})$

$\mathrm{Na}^{+}(\mathrm{mmol} / \mathrm{L})$

$\mathrm{K}^{+}(\mathrm{mmol} / \mathrm{L})$

$\mathrm{Cl}^{-}(\mathrm{mmol} / \mathrm{L})$

$\mathrm{iCa}(\mathrm{mmol} / \mathrm{L})$

GLU (mmol/L)

Bile acid

$(\mu \mathrm{mol} / \mathrm{L})$

Cholesterol

( $\mu \mathrm{mol} / \mathrm{L})$

GGT (U/L)

Tbil $(\mu \mathrm{mol} / \mathrm{L})$

$\mathrm{LDH}(\mathrm{U} / \mathrm{L})$

$\mathrm{BE}$, base excess; $\mathrm{Cl}^{-}$, chloride ion; GGT, glutamyl transpeptidase; GLU, glucose; $\mathrm{HCO}_{3}^{-}$, bicarbonate ion; iCa, ionised calcium; $\mathrm{K}^{+}$, potassium ion; $\mathrm{Lac}$, lactate; $\mathrm{LDH}$, lactate dehydrogenase; $\mathrm{Na}^{+}$, sodium ion; $\mathrm{PCO}_{2}$, partial pressure of carbon dioxide; $\mathrm{pH}$, pondus hydrogenii; $\mathrm{PO}_{2}$, partial pressure of oxygen; $\mathrm{sO}_{2}$, oxygen saturation; Tbil, total bilirubin.

12. Length of post-transplant ICU care.

13. Length of post-transplant hospital stay.

\section{Safety end points}

1. Graft rejection at POM 1, POM 6 and POM 12, including clinically diagnosed rejection and pathologically confirmed rejection with the Banff schema. ${ }^{40}$

2. Vascular complications at POM 1, POM 6 and POM 12 , including thrombosis, haemorrhage, embolism and stenosis of IVC, PV and HA. Patients will undergo a colour Doppler ultrasound at each time point, and digital subtraction angiography will be performed when necessary.

3. Acute kidney injury (AKI) within the first seven postoperative days. AKI will be graded according to the Kidney Disease: Improving Global Outcomes staging system. $^{41}$

4. Estimated glomerular filtration rate (eGFR) at POD 7, POD 14, POM 1, POM 6 and POM 12. eGFR will be judged according to the chronic kidney disease epidemiology collaboration creatinine equation. ${ }^{42}$

5. Need for renal replacement therapy following transplantation.

6. Recipient infection within POM 1. Infections will be defined on the basis of the standard criteria proposed by the Centers for Disease Control and Prevention. ${ }^{43}$
7. Cumulative complications at POM 1, POM 6 and POM 12. Complications will be graded according to the comprehensive complication index (CCI) based on Clavien-Dindo Classification. ${ }^{44}$

8. Adverse events (AE) and severe adverse events (SAE) will be assessed according to National Cancer Institute-Common Terminology Criteria for Adverse Events (NCI-CTCAE) (V.5.0) criteria at POM 1, POM 6 and POM 12.

9. Positive perfusate microbial culture rate. At the end of SCS or NMP, a sample will be collected for microbiological culture (cold preservation solution or warm perfusate).

10. Organ discard rate.

Self-reported end points

Quality of life will be scored using the EQ-5D questionnaire obtained before transplantation and at POM 1, POM 6 and POM 12.

Exploratory end points

1. Molecular biological data of IRI and the immune system will be evaluated in serum, plasma, whole blood, liver specimens, bile duct tissue and perfusate at the above time points during and after transplantation. The hepatic IRI will be evaluated based on the Suzuki 
Open access

Table 8 Follow-up period 1 (PODs 1-7)

$\begin{array}{lllllll}\text { POD 1* } & \text { POD } 2 & \text { POD 3 } & \text { POD 4 } & \text { POD 5 } & \text { POD 6 } & \text { POD 7 }\end{array}$

$\mathrm{Hb}(\mathrm{g} / \mathrm{L})$
WBC $\left(10^{9} / \mathrm{L}\right)$
$\mathrm{PLT}\left(10^{9} / \mathrm{L}\right)$
$\mathrm{NEUT} \%$
$\mathrm{CRP}(\mathrm{mg} / \mathrm{L})$
ALT $(\mathrm{U} / \mathrm{L})$
AST $(\mathrm{U} / \mathrm{L})$

Tbil $(\mu \mathrm{mol} / \mathrm{L})$

LDH (U/L)

Crea $(\mu \mathrm{mol} / \mathrm{L})$

ALB $(g / L)$

PA (mg/L)

ALP (U/L)

GGT (U/L)

$\mathrm{PCT}(\mathrm{ng} / \mathrm{mL})$

CK (U/L)

CK-MB (U/L)

Myoglobin (ng/mL)

High-sensitivity troponin $(\mathrm{ng} / \mathrm{mL})$

Endotoxin (Eu/ml)

Serum amylase (U/L)

Serum lipase (U/L)

$\mathrm{Ca}^{2+}(\mathrm{mmol} / \mathrm{L})$

Serum cystatin $(\mathrm{mg} / \mathrm{L})$

Urea (mmol/L)

Complement C1q (mg/L)

$\mathrm{P}^{2+}(\mathrm{mmol} / \mathrm{L})$

Retinol binding protein $(\mathrm{mg} / \mathrm{L})$

BNP $(\mathrm{pg} / \mathrm{mL})$

Ammonia (mg/L)

PT (S)

INR

$\mathrm{Fbg}(\mathrm{g} / \mathrm{L})$

D-Dimer (mg/L)

$\mathrm{pH} \dagger$

$\mathrm{BE}(\mathrm{mmol} / \mathrm{L}) \dagger$

$\mathrm{Lac}(\mathrm{mmol} / \mathrm{L}) \dagger$

$\mathrm{PO}_{2}(\mathrm{~mm} \mathrm{Hg}) \dagger$

$\mathrm{PCO}_{2}(\mathrm{~mm} \mathrm{Hg}) \dagger$

$\mathrm{HCO}_{3}^{-}(\mathrm{mmol} / \mathrm{L}) \dagger$

Blood cultureł

USł

Chest X-raył

$\square_{0} \mathrm{~N}_{1} \mathrm{Y} \quad \square_{0} \mathrm{~N}_{1} \mathrm{Y} \quad \square_{0} \mathrm{~N}_{1} \mathrm{Y} \quad \square_{0} \mathrm{~N}_{1} \mathrm{Y} \quad \square_{0} \mathrm{~N}_{1} \mathrm{Y} \quad \square_{0} \mathrm{~N}_{1} \mathrm{Y} \quad \square_{0} \mathrm{~N} \square_{1} \mathrm{Y}$

Complications



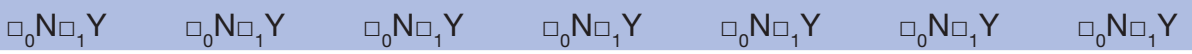

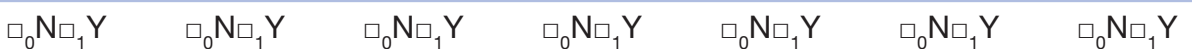

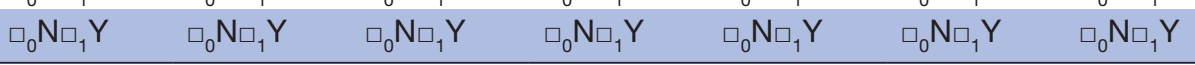

Continued 
Table 8 Continued

\begin{tabular}{|c|c|c|c|c|c|c|c|}
\hline & POD 1* & POD 2 & POD 3 & POD 4 & POD 5 & POD 6 & POD 7 \\
\hline Adverse events & $\square_{0} \mathrm{~N}_{1} \mathrm{Y}$ & $\square_{0} \mathrm{~N}_{1} \mathrm{Y}$ & $\square_{0} N \square_{1} \mathrm{Y}$ & $\square_{0} N \square_{1} \mathrm{Y}$ & $\square_{0} N \square_{1} \mathrm{Y}$ & $\square_{0} N \square_{1} \mathrm{Y}$ & $\square_{0} \mathrm{~N}_{\square_{1}} \mathrm{Y}$ \\
\hline Medication records & $\square_{0} N \square_{1} \mathrm{Y}$ & $\square_{0} \mathrm{~N}_{1} \mathrm{Y}$ & $\square_{0} N \square_{1} \mathrm{Y}$ & $\square_{0} \mathrm{~N}_{1} \mathrm{Y}$ & $\square_{0} N \square_{1} \mathrm{Y}$ & $\square_{0} N \square_{1} \mathrm{Y}$ & $\square_{0} \mathrm{~N} \square_{1} \mathrm{Y}$ \\
\hline Graft survival status & $\square_{0} \mathrm{~N} \square_{1} \mathrm{Y}$ & $\square_{0} \mathrm{~N}_{1} \mathrm{Y}$ & $\square_{0} \mathrm{~N} \square_{1} \mathrm{Y}$ & $\square_{0} N \square_{1} \mathrm{Y}$ & $\square_{0} \mathrm{~N} \square_{1} \mathrm{Y}$ & $\square_{0} \mathrm{~N} \square_{1} \mathrm{Y}$ & $\square_{0} \mathrm{~N}_{1} \mathrm{Y}$ \\
\hline
\end{tabular}

Blood culture: when the patient's body temperature is above $38^{\circ} \mathrm{C}$, blood culture should be carried out according to the patient's condition. Complications, adverse events and medication records are recorded in detail in the case report form.

*Blood examination $5-11$ hours after reperfusion.

†If the recipient is still in the ICU or needs arterial blood gas analysis.

‡Every other day within 1 week after operation.

ALB, albumin; ALP, alkaline phosphatase; ALT, alanine aminotransferase; AST, aspartate transaminase; BE, base excess; BNP, brain natriuretic peptide; CK, creatine kinase; CK-MB, creatine kinaseisoenzyme; Crea, creatinine; CRP, C-reactive protein; Fbg, fibrinogen; GGT, glutamyl transpeptidase; $\mathrm{Hb}$, haemoglobin; $\mathrm{HCO}_{3}-$, bicarbonate ion; INR, international normalized ratio; Lac, lactate; $\mathrm{LDH}$, lactate dehydrogenase; NEUT\%, neutrophilic granulocytepercentage; $\mathrm{P}^{2+}$, phosphonium ion; $\mathrm{PA}$, prealbumin; $\mathrm{PCO}_{2}$, partial pressure of carbon dioxide; $\mathrm{PCT}$, procalcitonin; $\mathrm{pH}$, pondus hydrogenii; PLT, platelets; $\mathrm{PO}_{2}$, partial pressure of oxygen; PT, prothrombin time; Tbil, total bilirubin; US, ultrasound; WBC, white blood cells.

score. ${ }^{46}$ Bile duct IRI will be evaluated based on the Hansen bile duct injury (BDI) score. ${ }^{47} 48$

2. Functional tests of coagulation, heart, lung, kidney, intestine, brain and other organs at the above time points during and after transplantation.

3 . The balance between medical expenditure and quality of life.

\section{Sample size}

This study has a 1:1 parallel design, and the sample size calculation is based on our pilot study. It is estimated that EAD will occur in $10 \%$ of the experimental (IFLT) group and $40 \%$ of the control (CLT) group. With a power of $80 \%(1-\beta)$ and significance level ( $\alpha$, two-sided) of $5 \%$, we calculated that 32 patients need to be enrolled in each arm. Considering the possibility of organ discard under special conditions, the sample size was increased by $5 \%$. Ultimately, 34 patients in each arm, for a total of 68 patients, will be enrolled in the study.

\section{Recruitment}

Recruitment began in February 2019 and will go until the target sample size is reached (expected: August 2020). The trial was designed as a prospective, randomised, controlled, single-centre clinical trial in patients on the waiting list undergoing liver transplantation. First, donor and recipient eligibility will be assessed before transplantation. Informed consent will be obtained. All the donors have to be in our hospital, and the donor livers will be allocated by COTRS. When a donor liver is allocated to an informed recipient of our own hospital, the recipient will be randomly assigned to the IFLT or CLT group. The number of recipients in the two groups will be allocated 1:1, and the grouping information will be open label. Postoperative monitoring, treatment and nursing will be performed according to the same standards and procedures. Intraoperative parameters, liver graft function, post-transplant complications and patient/graft survival will be observed and recorded. After a 12-month follow-up of the last enrolled recipient, the outcomes will be analysed to evaluate the safety and efficacy of IFLT in human liver transplantation. The research overview flow chart is shown in figure 1 .

\section{Randomisation and blinding}

This study is a randomised controlled trial, and block randomisation will be adopted for 1:1 random grouping. A subject randomisation list will be generated using a proven central randomisation system by the statistician, and random allocation numbers will be automatically handled by the system to avoid bias. When all the inclusion/exclusion criteria are fulfilled, the investigator will contact the central randomisation system to get a random number, and then the subject will be allocated to the experimental or control group based on the number. This is an open-label study. Because of the nature of the surgical procedure, it is not possible to blind the surgical team to the group allocation. Outcome assessors will be blinded where possible. This includes the diagnostician interpreting the medical imaging examination as well as the histopathologists interpreting the biopsy specimens.

\section{Data collection and management}

\section{Case report form/electronic database}

The investigators should input all subjects' original observation records timely, completely and correctly into the case report form (CRF). The data on the CRF will be transformed into an electronic database. The CRF and database will be reviewed by two independent inspectors for error checking, and then the completed data will be handed over to the data manager. If there are questions about a CRF, the data manager will send the Data Clarification Form (DCF) to the investigators and contact data inspectors to solve the doubtful points and return feedback. The data manager will confirm, modify and input data according to the feedback of investigators and send the DCF again if necessary. 
Table 9 Follow-up period 2 (POD 14 and discharge day)

\section{POD 14 Discharge day}

$\mathrm{Hb}(\mathrm{g} / \mathrm{L})$
WBC $\left(10^{9} / \mathrm{L}\right)$
PLT $\left(10^{9} / \mathrm{L}\right)$
NEUT\%
CRP $(\mathrm{mg} / \mathrm{L})^{\star}$
PCT $(\mathrm{ng} / \mathrm{mL})^{*}$
PT $(\mathrm{S})$
INR

$\mathrm{Fbg}(\mathrm{g} / \mathrm{L})$

D-Dimer $(\mathrm{mg} / \mathrm{L})^{\star}$

$\operatorname{ALT}(\mathrm{U} / \mathrm{L})$

AST (U/L)

Tbil $(\mu \mathrm{mol} / \mathrm{L})$

$\mathrm{LDH}(\mathrm{U} / \mathrm{L})$

Crea $(\mu \mathrm{mol} / \mathrm{L})$

ALB ( $g / L)$

$\mathrm{PA}(\mathrm{mg} / \mathrm{L})$

$\operatorname{ALP}(\mathrm{U} / \mathrm{L})$

GGT (U/L)

Ammonia (mg/L)*

Collection of blood specimens

US*

Performance status (ECOG)

Quality of life (EQ-5D)

\begin{tabular}{lll} 
Complications & $\square_{0} \mathrm{~N}_{1} \mathrm{Y}$ & $\square_{0} \mathrm{~N} \square_{1} \mathrm{Y}$ \\
Adverse events & $\square_{0} \mathrm{~N} \square_{1} \mathrm{Y}$ & $\square_{0} \mathrm{~N} \square_{1} \mathrm{Y}$ \\
Medication records & $\square_{0} \mathrm{~N}_{1} \mathrm{Y}$ & $\square_{0} \mathrm{~N} \square_{1} \mathrm{Y}$ \\
Recipient survival status & $\square_{1} \mathrm{~N} \square_{1} \mathrm{Y}$ & $\square_{0} \mathrm{~N} \square_{1} \mathrm{Y}$ \\
Graft survival status & $\square_{0} \mathrm{~N} \square_{1} \mathrm{Y}$ & ${ }_{0} \mathrm{~N} \square_{1} \mathrm{Y}$ \\
\hline
\end{tabular}

Complications, adverse events and medication records are recorded in detail in the case report form.

*If necessary.

ALB, albumin; ALP, alkaline phosphatase; ALT, alanine aminotransferase; AST, aspartate transaminase; Crea, creatinine; CRP, C-reactive protein; ECOG, Eastern Cooperative Oncology Group; EQ-5D, EuroQol-5 Dimension; Fbg, fibrinogen; GGT, glutamyl transpeptidase; $\mathrm{Hb}$, haemoglobin; INR, international normalized ratio; LDH, lactate dehydrogenase; NEUT\%, neutrophilic granulocyte percentage; PA, prealbumin; PCT, procalcitonin; PLT, platelets; PT, prothrombin time; Tbil, total bilirubin; US, ultrasound; WBC, white blood cells.

\section{Database locking}

After data review and confirmation, the data managers, main investigators, statistical analysts, sponsors and supervisors will jointly audit the data and complete the final definition of the analysis population. Then the data manager will lock the database. In general, locked databases or files should not be altered.
Data analysis

The final data will be submitted to the statistical analyst for statistical analysis.

\section{Analysis plan}

Analysis sets

1. Full analysis set: intention-to-treat (ITT). ITT analysis is a comparison of the treatment groups that includes all patients as originally allocated after randomisation.

2. Per-protocol set (PPS): per-protocol analysis is a comparison of treatment groups that includes only those patients who completed the treatment originally allocated.

The primary end point and secondary end points of the study will be analysed by ITT and PPS.

\section{Statistics}

1. The data analysis will be based on the principle of ITT, and all statistical analyses will adopt a two-sided test; $\mathrm{p}<0.05$ will be considered statistically significant. After the database is locked, the data analysis will be performed in STATA V.14.0 software (StataCorp).

2. Demographic information and baseline characteristics will be analysed using descriptive statistical analysis.

3 . The primary end point will be analysed using the $\chi^{2}$ test, and the absolute difference and $95 \%$ CI will be calculated.

4. Analysis of secondary end point: the two-category variables will be analysed using the $\chi^{2}$ test or logistic regression to report the OR value after adjusting for confounding factors. For the continuous variables, Student's t-test will be used if the normal distribution is satisfied; otherwise, the Mann-Whitney U test will be used, or the mixed model with repeated measurement will be used to analyse the change of the individual from the baseline. The time data will be analysed by the Kaplan-Meier method, and the log-rank test and a Cox regression model will also be used.

5. Missing data: if EAD is missing, it will be replaced by the worst-value method, and $\mathrm{EAD}$ will be considered. Secondary values will be replaced in two ways: (1) multiple imputation and missing values will be estimated by independent simulation variables according to the characteristics of the predicted values and the availability of the data. Linear regression will be used for continuous variables, logistic regression for binary categorical variables, ordered logistic regression for ordered multiclass variables and disordered multiclass logistic regression for disordered multiclass variables. Twenty data sets will be created by the multiple imputation method, and the final result will be obtained by averaging the results of the 20 data sets using the Rubin rule, ensuring that the SE of all regression coefficients takes into account the uncertainty of the simulation and the uncertainty of the estimate; (2) sensitivity analysis involves directly eliminating missing values, deeming treatment ineffectiveness as well as optimal and 
Table 10 Follow-up period (within 1 year after discharge)

POM $1 \quad$ POM 2

POM 3

POM 4

POM 5

POM 6

POM 12

$\mathrm{Hb}(\mathrm{g} / \mathrm{L})$

WBC $\left(10^{9} / \mathrm{L}\right)$

PLT $\left(10^{9} / \mathrm{L}\right)$

NEUT\%

CRP $(\mathrm{mg} / \mathrm{L})^{*}$

PCT $(\mathrm{ng} / \mathrm{mL})^{\star}$

PT (S)

INR

$\mathrm{Fbg}(\mathrm{g} / \mathrm{L})$

D-Dimer (mg/L)*

ALT (U/L)

AST (U/L)

Tbil $(\mu \mathrm{mol} / \mathrm{L})$

LDH (U/L)

Crea $(\mu \mathrm{mol} / \mathrm{L})$

ALB $(g / L)$

$\mathrm{PA}(\mathrm{mg} / \mathrm{L})$

ALP (U/L)

GGT (U/L)

Ammonia (mg/L)*

Collection of blood specimens

MRCP†

US*

Performance status (ECOG)

Quality of life (EQ-5D)

\begin{tabular}{|c|c|c|c|c|c|c|c|c|}
\hline Complications & $\square_{0} \mathrm{~N} \square_{1} \mathrm{Y}$ & $\square_{0} N \square_{1} \mathrm{Y}$ & $\square_{0} \mathrm{~N} \square_{1} \mathrm{Y}$ & $\square_{0} \mathrm{~N} \square_{1} \mathrm{Y}$ & $\square_{0} \mathrm{~N} \square_{1} \mathrm{Y}$ & $\square_{0} \mathrm{~N} \square_{1} \mathrm{Y}$ & $\square_{0} \mathrm{~N} \square_{1} \mathrm{Y}$ & $\square_{0} \mathrm{~N} \square_{1} \mathrm{Y}$ \\
\hline Adverse events & $\square_{0} \mathrm{~N}_{1} \mathrm{Y}$ & $\square_{0} \mathrm{~N} \square_{1} \mathrm{Y}$ & $\square_{0} \mathrm{~N}_{1} \mathrm{Y}$ & $\square_{0} N \square_{1} \mathrm{Y}$ & $\square_{0} N \square_{1} \mathrm{Y}$ & $\square_{0} \mathrm{~N} \square_{1} \mathrm{Y}$ & $\square_{0} N \square_{1} \mathrm{Y}$ & $\square_{0} \mathrm{~N}_{1} \mathrm{Y}$ \\
\hline Medication records & $\square_{0} \mathrm{~N}_{1} \mathrm{Y}$ & $\square_{0} \mathrm{~N} \square_{1} \mathrm{Y}$ & $\square_{0} \mathrm{~N} \square_{1} \mathrm{Y}$ & $\square_{0} \mathrm{~N} \square_{1} \mathrm{Y}$ & $\square_{0} \mathrm{~N} \square_{1} \mathrm{Y}$ & $\square_{0} \mathrm{~N} \square_{1} \mathrm{Y}$ & $\square_{0} \mathrm{~N} \square_{1} \mathrm{Y}$ & $\square_{0} \mathrm{~N} \square_{1} \mathrm{Y}$ \\
\hline Recipient survival status & $\square_{0} \mathrm{~N}_{1} \mathrm{Y}$ & $\square_{0} \mathrm{~N}_{1} \mathrm{Y}$ & $\square_{0} \mathrm{~N} \square_{1} \mathrm{Y}$ & $\square_{0} \mathrm{~N} \square_{1} \mathrm{Y}$ & $\square_{0} \mathrm{~N} \square_{1} \mathrm{Y}$ & $\square_{0} \mathrm{~N} \square_{1} \mathrm{Y}$ & $\square_{0} \mathrm{~N} \square_{1} \mathrm{Y}$ & $\square_{0} \mathrm{~N} \square_{1} \mathrm{Y}$ \\
\hline Graft survival status & $\square_{0} N \square_{1} \mathrm{Y}$ & $\square_{0} \mathrm{~N} \square_{1} \mathrm{Y}$ & $\square_{0} \mathrm{~N} \square_{1} \mathrm{Y}$ & $\square_{0} \mathrm{~N} \square_{1} \mathrm{Y}$ & $\square_{0} \mathrm{~N} \square_{1} \mathrm{Y}$ & $\square_{0} \mathrm{~N} \square_{1} \mathrm{Y}$ & $\square_{0} N \square_{1} \mathrm{Y}$ & $\square_{0} \mathrm{~N} \square_{1} \mathrm{Y}$ \\
\hline
\end{tabular}

Complications, adverse events and medication records are recorded in detail in the case report form.

*If necessary.

†All patients undergo MRCP at 6 and 12 months after transplantation.

ALB, albumin; ALP, alkaline phosphatase; ALT, alanine aminotransferase; AST, aspartate transaminase; Crea, creatinine; CRP, C-reactive protein; ECOG, Eastern Cooperative Oncology Group; EQ-5D, EuroQol-5 Dimension; Fbg, fibrinogen; GGT, glutamyl transpeptidase; Hb, haemoglobin; INR, international normalized ratio; LDH, lactate dehydrogenase; MRCP, magnetic resonance cholangio pancreatography; NEUT\%, neutrophilic granulocyte percentage; PA, prealbumin; PCT, procalcitonin; PLT, platelets; PT, prothrombin time; Tbil, total bilirubin; US, ultrasound; WBC, white blood cells.

worst-case analysis. Sensitivity analysis will be used to compare the consistency of the primary results.

\section{Monitoring and safety}

AEs that occur during the study should be addressed in accordance with well-established management criteria that will support the life and health of the study subjects. It is the responsibility of the investigators to collect and record all
AEs occurring throughout the study. All AEs will be documented on the CRF. All SAEs should be reported to the superintendent and the ethics committee in a specialised SAE from. The causes and effects of SAE will be carefully assessed, and the study will be suspended or terminated if necessary. All SAEs will be followed up to resolution. Recording and reporting of AEs will continue until the last enrolled patient has accomplished 12 months of follow-up. 
Donor inclusion criteria:

1. Donation after brain death (DBD)

2. Over the age of 18 years, or over the age of 14 years with body weight $>50 \mathrm{~kg}$

3. The donor liver is allocated to a recipient at our own hospital

Donor exclusion criteria:

1. Livers intended for split or reduced-size transplantation

2. High risk of transmitted infections (HIV infection and active tuberculosis)

3. Risk of donor malignancy transmission over $10 \%$ according to the DTAC categorisations
Recipient inclusion criteria:

1. Age $18-75$ years

2. End-stage liver disease and active on the waiting list for liver transplantation.

3. Agreed to receive liver grafts from deceased donors

4. Able to give informed consent

5. Able to comply with the study protocol

Recipient exclusion criteria:

1. Waiting for multivisceral or combined organ transplantation

2. ABO-incompatible liver transplantation

3. Primary liver cancer beyond the UCSF criteria

4. Fulminant liver failure

5. Current pregnancy

6. A history of organ transplantation

7. Contraindications defined by the AASLD liver transplant practice guidelines except MELD score $<15$

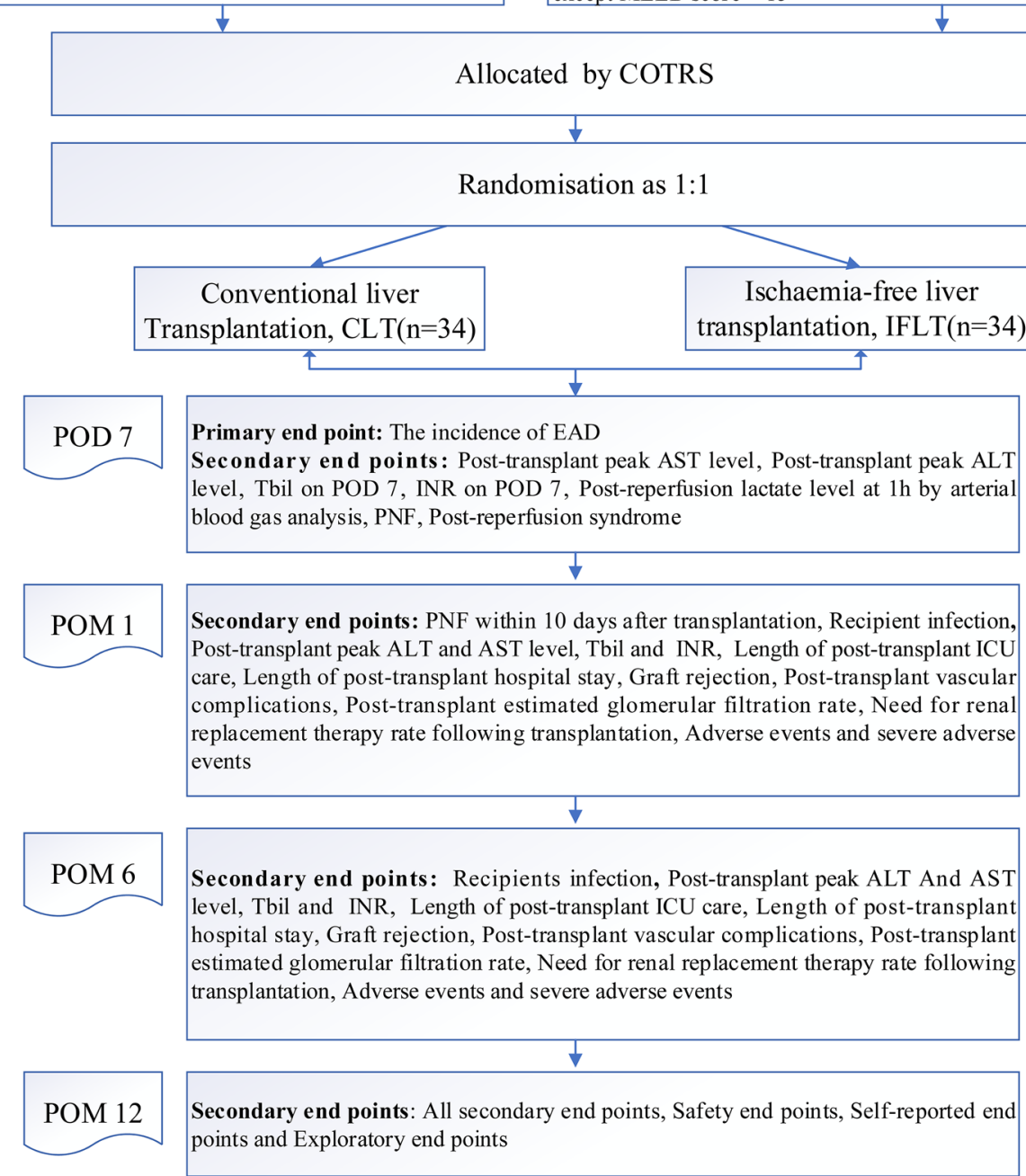

Figure 1 Brief flow chart of this study. AASLD, American Association for the Study of Liver Diseases; ALT, alanine aminotransferase; AST, aspartate transaminase; COTRS, China Organ Transplant Response System; DTAC, Disease Transmission Advisory Committee; EAD, early allograft dysfunction; ICU, intensive care unit; INR, international normalised ratio; MELD, model for end-stage liver disease; PNF, primary non-function; POD, postoperative day; POM, postoperative month; Tbil, total bilirubin; UCSF, University of California at San Francisco.

\section{AEs and complications}

AEs are defined as any unintended medical events that occur in patients participating in the trial. An AE does not necessarily have to have a causal relationship with the trial. Complications are AEs that deviate from the ideal postoperative course, are not inherent in the procedure and do not comprise a failure to cure.

The following scenarios are considered SAEs:

1. Death of the recipient.

2. Life-threatening complications. 
3. Persistent or severe disability.

4. Significantly prolonged hospital stay.

5. Other severe events as judged by the investigators.

AEs should be judged and graded according to NCICTCAE 5.0 and documented in the CRF. Complications should be categorised by Clavien-Dindo classification and scored against the CCI at each follow-up period. ${ }^{44}$

Withdrawal of trial

Withdrawal initiated by investigators

The investigators will initiate withdrawal in any of the following circumstances:

1. Severe violation of the study protocol occurs due to donor liver, perfusion or recipient reasons in the process of procurement, preservation, implantation or even discarding of the donor liver.

2. The subject suffers from certain diseases that are not suitable for participating in the study.

3. Safety or tolerance is disturbed by poor compliance.

4. Continued treatment will hurt the health of the subjects.

\section{Withdrawal initiated by subjects}

Subjects can decide to cease participation in this trial at any time for any reason. The reasons for their withdrawal should be acknowledged and documented.

\section{Withdrawal procedure}

1. If the subject withdraws without liver transplant, the subject can be re-added to the waiting list.

2. If the subject withdraws after liver transplant, the subject still can be receive standardised treatment, nursing and follow-up.

3. When a subject has an emergency that requires immediate termination of an ongoing liver transplant or subsequent therapy, the subject should be observed and evaluated accordingly while ensuring safety.

The reasons and time points of any withdrawal should be clearly collected and documented, and the observation and evaluation should be carried out accordingly. When an AE occurs, it must be tracked until it disappears. The CRF of any subject who received treatment but failed to complete the study should be retained, and the last test results will be transferred as the final results. Treatment response, tolerance and AEs will be analysed based on full data analysis.

\section{Specimen collection}

Written informed consent is required before all clinical specimens are collected. Complete and standard specimens enable the comparison between the experimental group and the control group under the same conditions, making the experimental data accurate and reliable. The sponsor will organise a clinical specimen collection team and establish a specimen bank. Body fluids, solid tissues and their derivatives (such as DNA, RNA, protein, etc) will be collected and preserved for related research and experiments. It is the responsibility of the investigators to participate in and supervise the process of specimen collection. All remaining samples must be destroyed within 15 years of the end of the clinical trial.

Before the operation, donor blood will be collected for extracting supernatant and peripheral mononuclear blood cells. After organ retrieval, part of the spleen and iliac vessels will be preserved. In total, three excision biopsies will be harvested from the donor liver: before retrieval, at the end of preservation and after graft re-vascularisation. Two biopsies will be harvested from the donor common bile duct: immediately after procurement and before common bile duct anastomosis following graft re-vascularisation. Perfusate samples will be collected repeatedly during machine perfusion. Bile (if produced) will be collected from a common bile duct tube. Recipient blood samples will be taken preoperatively; on PODs $1,3,5,7$, and 14 and in every POM during the follow-up period. Liver biopsy samples will be taken at POM 6 or when rejection is suspected.

\section{DISCUSSION}

Liver transplantation is an effective therapy for patients with end-stage liver disease. However, there are still many burdens that hamper the progress of liver transplantation. Donor liver IRI is an inevitable event in the current transplant procedure that often compromises transplant outcomes and increases the organ discard rate. ${ }^{10-13}$ Tremendous achievements have been made in the field of alleviating donor liver IRI. ${ }^{19-21}{ }^{23}$ Among these techniques, NMP has been successfully used in clinical practice in several transplant centres. Nasralla et al reported that liver transplantation with the help of NMP is associated with a decrease of $50 \%$ in graft injury and $50 \%$ in the organ discard rate and an increase of $54 \%$ in preservation time. ${ }^{19}$ However, IRI still cannot be fully avoided due to the existence of hypothermia, ischaemia and hypoxia in the surgical procedure. With surgical innovation, IFLT has enabled complete elimination of hypothermia, ischaemia and hypoxia during the whole transplant procedure. ${ }^{27}$ Our pilot study demonstrated its feasibility, safety and efficacy, with diminished peak injury markers and lower incidence of EAD compared with CLT. ${ }^{49}$ Although the results of the pilot study were promising, the nonrandomised design was a drawback. The purpose of this study is to further explore the efficacy and safety of IFLT in a randomised controlled trial.

A potential shortcoming of this study is the single source of DBD donors and the exclusion of donation after cardiac death (DCD) because it is difficult to perform IFLT using DCD organs. However, it is possible to combine in situ regional normothermic perfusion (NRP) and IFLT in such donors. Donors with high risks of communicable infectious diseases or malignancy are excluded for the safety of participants. For recipients, patients with fulminant liver failure and primary hepatocellular carcinoma beyond the UCSF criteria are not included in this trial due to their high risk of complications and mortality. In addition, patients with a history of 
organ transplantation, multiple-organ transplantation or combined organ transplantation and ABO-incompatible liver transplantation are excluded because different surgical or post-transplant management protocols are used in these patients.

Due to the increased organ shortage, an increasing number of livers from extended-criteria donors (ECDs), such as elderly donors and donors with hepatosteatosis, are used worldwide. When compared with organs of standard-criteria donors (SCD), ECD organs are more vulnerable to IRI and are associated with high risks of morbidity and mortality. ${ }^{5}$ Since IFLT might be able to prevent IRI, ECD livers might be an appropriate indication for IFLT. Indeed, the first case of IFLT successfully resuscitated a donor liver with $85 \%-90 \%$ macrovesicular steatosis. ${ }^{28}$ However, the donors are not limited to ECD donors in the current study, because the benefits of IFLT in either SCD or ECD livers have not been confirmed in a randomised study. In addition, IFLT is an extreme example of NMP. The advantage of NMP over static cold storage is still under debate, although a randomised study was recently reported. ${ }^{19}$ Therefore, we did not design this study to compare IFLT with CLT using NMP as a preservation method in the current study. Another randomised controlled study is being planned in our centre to compare the safety and efficacy of these two methods in ECD livers.

The primary end point of this trial is the incidence of EAD after liver transplantation. EAD represents a severe form of clinical IRI, serving as an important surrogate end point in liver transplantation. ${ }^{50}$ The definition of EAD is largely based on serum AST/ALT in the recipient. The use of EAD (based on this definition) in the setting of NMP was recently criticised. ${ }^{51}$ We agree that EAD is not a perfect end point. However, the first randomised controlled study used it as an important end point, ${ }^{19}$ and it is the most frequently used primary end point in the current registered trials concerning the use of machine perfusion techniques. The Food and Drug Administration insists on EAD in the current NMP trials. ${ }^{52}$ The Zurich group is using the complication score (ClavienDindo) in their current HOPE trial, and the Groningen group is using ischaemic cholangiopathy in DCD liver transplantation. Therefore, we included these two end points as secondary and safety end points in the current study.

Undoubtedly, there are limitations concerning the IFLT procedure. First, the procedure is complicated and labour-intensive. Both experienced surgeons and perfusionists are required for a successful IFLT operation. Therefore, it is difficult to conduct a multicentre study at this moment. Further modification of the procedure is required. In addition, the NMP device used in our centre is non-transportable. For this reason, the donors and recipients have to be from the same medical institution. In the future, simplified IFLT techniques with a portable NMP device are required to yield a novel multicentre procedure.
In conclusion, this study is a single-centre trial designed to assess the incidence of IRI-related complications between IFLT and CLT recipients, as well as allograft/ recipient survival, to further validate the efficacy and safety of IFLT. The results from this trial can provide important evidence for the potential benefits of IFLT.

\section{Patient and public involvement}

The patients and public were not involved in the design and conduct of the study.

\section{Ethics and dissemination}

This trial will be conducted in accordance with the principles of the 1964 Declaration of Helsinki and its later amendments. All organs used in this study will be procured from brain-dead volunteer donors. The diagnosis of brain death has to be made by two independent, qualified neurologists. Donors were not prisoners, and no biological material was sourced from prisoners. Written informed content has to be obtained from all the directive family members for each donor, and all the organs have to be allocated through the COTRS. We have already provided evidence to the journal to verify that the above criteria will be met.

The protocol was viewed and approved by the Ethics Committee of the First Affiliated Hospital, Sun Yat-sen University. The ethical approval number is (2019)037. All documents communicating with the ethics committee will be kept in the researcher's folder. If it is necessary to modify this protocol during clinical research, it will be reviewed by the hospital ethics committee and implemented after approval. Written informed consent will be obtained from each subject prior to organ allocation and randomisation. The objectives and methods, benefits, possible risks and solutions, specimen collection plan and corresponding compensation when damage occurs will be clarified clearly for all subjects. All subjects have the right to cease participation in this trial at any time for any reason. Informed consent for this study and any changes in the course of this study must be reviewed and approved by the ethics committee before applying.

With regard to dissemination, the results of this study will be published in an academic journal and presented at national and international conferences.

\section{Author affiliations}

${ }^{1}$ Organ Transplant Center, The First Affiliated Hospital, Sun Yat-sen University, Guangzhou, China

${ }^{2}$ Guangdong Provincial Key Laboratory of Organ Donation and Transplant Immunology, Guangzhou, China

${ }^{3}$ Guangdong Provincial International Cooperation Base of Science and Technology (Organ Transplantation), Guangzhou, China

${ }^{4}$ Department of Anesthesiology, The First Affiliated Hospital, Sun Yat-sen University, Guangzhou, China

${ }^{5}$ State Key Laboratory of Ophthalmology, Zhongshan Ophthalmic Center, Sun Yatsen University, Guangzhou, China

${ }^{6}$ Department of Cardiopulmonary Bypass, The First Affiliated Hospital, Sun Yat-sen University, Guangzhou, China

${ }^{7}$ Surgical Intensive Care Unit, The First Affiliated Hospital, Sun Yat-sen University, Guangzhou, China 
Contributors The initial study concept was derived from the initiating investigator study group (XH, ZG, QZ, WJ, DW, MC, LWu, YM, AH, XZ). CH, SH and YT drafted the manuscript. ZG and JZ performed the sample size estimation. CH, SH, YT, LY, ZZhang, ZZhu, LWang, CZ, YZ, CS, WX, YS, XC, JR and CC participated in designing the study, preparing the revised protocol and are investigators at The First Affiliated Hospital, Sun Yat-sen University. All authors were involved in revising the manuscript and approved the final version.

Funding This work was supported by grants as follows: the National Natural Science Foundation of China (81970564, 81471583 and 81570587), the Key Clinical Specialty Construction Project of National Health and Family Planning Commission of the People's Republic of China, the Guangdong Provincial Key Laboratory Construction Projection on Organ Donation and Transplant Immunology (2013A061401007 and 2017B030314018), Guangdong Provincial international Cooperation Base of Science and Technology (Organ Transplantation) (2015B050501002), Guangdong Provincial Natural Science Funds for Major Basic Science Culture Project (2015A030308010), Guangdong Provincial Natural Science Funds for Distinguished Young Scholars (2015A030306025), Special support programme for training high-level talents in Guangdong Province (2015TQ01R168), Pearl River Nova Program of Guangzhou (201506010014) and Science and Technology Program of Guangzhou (201704020150).

Competing interests None declared.

Patient and public involvement Patients and/or the public were not involved in the design, conduct, reporting or dissemination plans of this research.

Patient consent for publication Not required.

Provenance and peer review Not commissioned; externally peer reviewed.

Open access This is an open access article distributed in accordance with the Creative Commons Attribution Non Commercial (CC BY-NC 4.0) license, which permits others to distribute, remix, adapt, build upon this work non-commercially, and license their derivative works on different terms, provided the original work is properly cited, appropriate credit is given, any changes made indicated, and the use is non-commercial. See: http://creativecommons.org/licenses/by-nc/4.0/.

\section{ORCID iD}

Changjun Huang http://orcid.org/0000-0002-7411-7637

\section{REFERENCES}

1 Wang F-S, Fan J-G, Zhang Z, et al. The global burden of liver disease: the major impact of China. Hepatology 2014;60:2099-108.

2 Xiao J, Wang F, Wong N-K, et al. Global liver disease burdens and research trends: analysis from a Chinese perspective. $J$ Hepatol 2019;71:212-21.

3 Zarrinpar A, Busuttil RW. Liver transplantation: past, present and future. Nat Rev Gastroenterol Hepatol 2013;10:434-40.

4 Saidi RF, Hejazii Kenari SK. Challenges of organ shortage for transplantation: solutions and opportunities. Int J Organ Transplant Med 2014;5:87-96.

5 Durand F, Renz JF, Alkofer B, et al. Report of the Paris consensus meeting on expanded criteria donors in liver transplantation. Liver Transpl 2008;14:1694-707.

6 Dubbeld J, Hoekstra H, Farid W, et al. Similar liver transplantation survival with selected cardiac death donors and brain death donors. Br J Surg 2010;97:744-53.

7 Starzl TE, Hakala TR, Shaw BW, et al. A flexible procedure for multiple cadaveric organ procurement. Surg Gynecol Obstet 1984;158:622-30.

8 Belzer FO, Southard JH. Principles of solid-organ preservation by cold storage. Transplantation 1988;45:673-6.

9 Maathuis M-HJ, Leuvenink HGD, Ploeg RJ. Perspectives in organ preservation. Transplantation 2007;83:1289-98.

10 Souidi N, Stolk M, Seifert M. Ischemia-Reperfusion injury: beneficial effects of mesenchymal stromal cells. Curr Opin Organ Transplant 2013;18:34-43.

11 Solhjou Z, Uehara M, Bahmani B, et al. Novel application of localized Nanodelivery of anti-interleukin-6 protects organ transplant from ischemia-reperfusion injuries. Am J Transplant 2017;17:2326-37.

12 de Rougemont O, Dutkowski P, Clavien P-A. Biological modulation of liver ischemia-reperfusion injury. Curr Opin Organ Transplant 2010;15:183-9.

13 Rauen $\mathrm{U}$, de Groot $\mathrm{H}$. New insights into the cellular and molecular mechanisms of cold storage injury. J Investig Med 2004;52:299-309.

14 Cursio R, Gugenheim J, Injury I-R. Ischemia-Reperfusion injury and Ischemic-Type biliary lesions following liver transplantation. $J$ Transplant 2012;2012:1-17.
15 Deschenes M. Early allograft dysfunction: causes, recognition, and management. Liver Transpl 2013;19 Suppl 2:S6-8.

16 Neves DB, Rusi MB, Diaz LGG, et al. Primary graft dysfunction of the liver: definitions, diagnostic criteria and risk factors. Einstein 2016;14:567-72.

17 Zhu Z, Tang Y, Huang S, et al. Donor liver apoptosis is associated with early allograft dysfunction and decreased short-term graft survival after liver transplantation. Clin Transplant 2018;32:e13438.

18 Eltzschig HK, Eckle T. Ischemia and reperfusion--from mechanism to translation. Nat Med 2011;17:1391-401.

19 Nasralla D, Coussios CC, Mergental H, et al. A randomized trial of normothermic preservation in liver transplantation. Nature 2018;557:50-6.

20 Nasralla D, Ploeg R, Coussios C, et al. Outcomes from a multinational randomised controlled trial comparing normothermic machine perfusion with static cold storage in human liver transplantation. American Journal of Transplantation 2017;17:404-04.

21 Ceresa CDL, Nasralla D, Knight S, et al. Cold storage or normothermic perfusion for liver transplantation: probable application and indications. Curr Opin Organ Transplant 2017;22:300-5

22 Moers C, Smits JM, Maathuis M-HJ, et al. Machine perfusion or cold storage in deceased-donor kidney transplantation. N Engl J Med 2009;360:7-19.

23 Ravikumar R, Jassem W, Mergental H, et al. Liver transplantation after ex vivo normothermic machine preservation: a phase 1 (first-inman) clinical trial. Am J Transplant 2016;16:1779-87.

24 Cypel M, Yeung JC, Liu M, et al. Normothermic ex vivo lung perfusion in clinical lung transplantation. $N$ Engl J Med 2011;364:1431-40.

25 Warnecke G, Moradiellos J, Tudorache I, et al. Normothermic perfusion of donor lungs for preservation and assessment with the organ care system lung before bilateral transplantation: a pilot study of 12 patients. Lancet 2012;380:1851-8.

26 Dhital KK, lyer A, Connellan M, et al. Adult heart transplantation with distant procurement and ex-vivo preservation of donor hearts after circulatory death: a case series. Lancet 2015;385:2585-91.

$27 \mathrm{He}$ X, Guo Z, Zhao Q, et al. The first case of ischemia-free organ transplantation in humans: a proof of concept. Am J Transplant 2018;18:737-44.

28 Zhao $Q$, Huang $S$, Wang $D$, et al. Does ischemia free liver procurement under normothermic perfusion benefit the outcome of liver transplantation? Ann Transplant 2018;23:258-67.

29 Chan A-W, Tetzlaff JM, Gøtzsche PC, et al. Spirit 2013 explanation and elaboration: guidance for protocols of clinical trials. BMJ 2013;346:e7586.

30 Nalesnik MA, Woodle ES, Dimaio JM, et al. Donor-transmitted malignancies in organ transplantation: assessment of clinical risk. Am J Transplant 2011:11:1140-7.

31 Yao FY, Ferrell L, Bass NM, et al. Liver transplantation for hepatocellular carcinoma: expansion of the tumor size limits does not adversely impact survival. Hepatology 2001;33:1394-403.

32 Martin P, DiMartini A, Feng S, et al. Evaluation for liver transplantation in adults: 2013 practice guideline by the American association for the study of liver diseases and the American Society of transplantation. Hepatology 2014;59:1144-65.

33 Laing RW, Mergental H, Yap C, et al. Viability testing and transplantation of marginal livers (VITTAL) using normothermic machine perfusion: study protocol for an open-label, nonrandomised, prospective, single-arm trial. BMJ Open 2017;7:e017733.

34 Olthoff KM, Kulik L, Samstein B, et al. Validation of a current definition of early allograft dysfunction in liver transplant recipients and analysis of risk factors. Liver Transp/ 2010;16:943-9.

35 Jochmans I, Monbaliu D, Pirenne J. The beginning of an end point: peak AST in liver transplantation. J Hepatol 2014;61:1186-7.

36 Broering DC, Topp S, Schaefer U, et al. Split liver transplantation and risk to the adult recipient: analysis using matched pairs. J Am Coll Surg 2002;195:648-57.

37 Siniscalchi A, Gamberini L, Bardi T, et al. Post-reperfusion syndrome during orthotopic liver transplantation, which definition best predicts postoperative graft failure and recipient mortality? J Crit Care 2017;41:156-60.

38 Novellas S, Caramella T, Fournol M, et al. Mr cholangiopancreatography features of the biliary tree after liver transplantation. AJR Am J Roentgenol 2008;191:221-7.

39 Boraschi P, Donati F, Gigoni R, et al. Ischemic-type biliary lesions in liver transplant recipients: evaluation with magnetic resonance cholangiography. Transplant Proc 2004;36:2744-7.

40 Banff schema for grading liver allograft rejection: an international consensus document. Hepatology 1997;25:658-63. 
41 Khwaja A. KDIGO clinical practice guidelines for acute kidney injury. Nephron Clin Pract 2012;120:c179-84.

42 Inker LA, Schmid CH, Tighiouart H, et al. Estimating glomerular filtration rate from serum creatinine and cystatin C. N Engl J Med 2012;367:20-9.

43 Horan TC, Andrus M, Dudeck MA. CDC/NHSN surveillance definition of health care-associated infection and criteria for specific types of infections in the acute care setting. Am J Infect Control 2008;36:309-32.

44 Dindo D, Demartines N, Clavien P-A. Classification of surgical complications: a new proposal with evaluation in a cohort of 6336 patients and results of a survey. Ann Surg 2004;240:205-13.

45 Slankamenac K, Graf R, Barkun J, et al. The comprehensive complication index: a novel continuous scale to measure surgical morbidity. Ann Surg 2013;258:1-7.

46 Suzuki S, Toledo-Pereyra LH, Rodriguez FJ, et al. Neutrophil infiltration as an important factor in liver ischemia and reperfusion injury. modulating effects of FK506 and cyclosporine. Transplantation 1993;55:1265-72.

47 op den Dries S, Westerkamp AC, Karimian N, et al. Injury to peribiliary glands and vascular plexus before liver transplantation predicts formation of non-anastomotic biliary strictures. $J$ Hepatol 2014;60:1172-9.

48 Hansen T, Hollemann D, Pitton MB, et al. Histological examination and evaluation of donor bile ducts received during orthotopic liver transplantation--a morphological clue to ischemic-type biliary lesion? Virchows Arch 2012;461:41-8.

$49 \mathrm{He}$ X, Guo Z, Ju W, et al. Improved transplant outcomes in IschemiaFree liver transplantation: a report of the first 30 cases. American Journal of Transplantation 2019;19:354-5.

50 Croome KP, Hernandez-Alejandro R, Chandok N. Early allograft dysfunction is associated with excess resource utilization after liver transplantation. Transplant Proc 2013;45:259-64.

51 Dutkowski P, Guarrera JV, de Jonge J, et al. Evolving trends in machine perfusion for liver transplantation. Gastroenterology 2019;156:1542-7.

52 Quintini C, Martins PN, Shah S, et al. Implementing an innovated preservation technology: the American Society of transplant surgeons' (ASTS) standards Committee white paper on ex situ liver machine perfusion. Am J Transplant 2018;18:1865-74. 